\title{
PAPER
}

\section{Cognitive dysfunction in young men following head injury in childhood and adolescence: a population study}

\author{
T W Teasdale, A W Engberg
}

J Neurol Neurosurg Psychiatry 2003;74:933-936

See end of article for authors' affiliations ....................

Correspondence to: Dr T W Teasdale, Department of Psychology, University of Copenhagen,

Amager, Njalsgade 88 2300 Copenhagen $S$ Denmark;

tom.teasdale@psy.ku.dk

Received 4 January In revised form

25 February 2003

Accepted

26 February 2003

\begin{abstract}
Objectives: To examine the prevalence of cognitive dysfunction among young men who had suffered a head injury during childhood or adolescence, in particular focusing upon the effects of age and the severity of the injury.

Methods: By cross linkage of Danish national registers for hospital admissions and the draft board, 3091 young men were identified who had been injured before age 18 and tested at age 18 or shortly thereafter: 970 had suffered a single concussion and were in hospital for one day only; 521 had two concussions at separate times and were in hospital for one day only on each occasion; 961 had a cranial fracture; and 639 had a cerebral lesion. For all of these, scores on the draft board's cognitive screening test were obtained, dichotomised as dysfunctional or non-dysfunctional. Prevalences of dysfunctional scores were compared with population base rates (about $20 \%$ of all Danish men appearing before the draft board had a score classified as dysfunctional).

Results: For young men who had suffered a single concussion, cranial fracture, or cerebral lesion before 12 years of age, resulting in less than 12 days of hospital admission $(n=376)$, rates of cognitive dysfunction did not exceed those in the general population (odds ratios $<1.4, \mathrm{NS}$ ), but the odds ratios became significant and $>1.4$ where the injury occurred after age 11 . For those with a cerebral lesion resulting in over 11 days of hospital admission $(n=263)$, all odds ratios were significant and $\geqslant 2.0$, irrespective of age at injury. For cases of two concussions, all odds ratios were $>1.4$ but were not significant for all age groupings.

Conclusions: For milder forms of single head injury before age 12 there is no evidence of enduring cognitive dysfunction. The apparent effect at later ages may reflect predisposing psychosocial factors. For more serious injury, and for cases with two concussions, the effect is marked and not clearly related to age. For the former, this suggests enduring neurological effects of the injury; for the latter, where the effect is unrelated to time between injuries, predisposing factors may again play a role.
\end{abstract}

S evere head injury in childhood and adolescence has repeatedly been shown to result in cognitive dysfunction. ${ }^{1}$ There remains, however, uncertainty over possible differential effects of age at injury, and earlier perceptions that recovery is better at young ages $^{2-4}$ are now questioned..$^{5-7}$ There have also hitherto been comparatively few studies that have examined the continuing consequences of pre-adult head injury on cognitive functioning in adulthood, and here too results have been conflicting. ${ }^{8-10}$ With regard to mild head injury, most evidence points to substantial recovery of cognitive functioning within at most weeks, regardless of age, ${ }^{11}$ although again some studies have suggested enduring consequences. ${ }^{52}{ }^{13}$ Especially complex is the not infrequent situation of repeated mild head injury, where cumulative effects have been reported. ${ }^{14}{ }^{15}$

Most studies have employed comparatively small samples, not usually epidemiologically based. In the present study we have determined the prevalence of cognitive dysfunction in large and population derived numbers of young men who have sustained either severe or mild head injury in childhood or adolescence, including a group who have sustained two separate mild injuries.

\section{METHODS}

The study involved cross linking two national Danish registers, one concerning hospital admissions ${ }^{16}$ and the other concerning conscription. ${ }^{17}$ The link was made possible as both registers employ the same identity number.

\section{Hospital admissions register}

The Danish national computer register of hospital admissions has recorded data on all patients discharged from Danish hospitals since 1979. These data include admission and discharge dates, together with discharge diagnoses. Our own database was drawn from live discharges between 1979 and 1993, with any diagnosis indicating head injury. During this time period diagnoses were recorded according to the International Classification of Diseases, 8th edition (ICD-8). We defined four groups:

- Single concussion: patients who during the 15 year period had been admitted once to hospital for not more than one day and whose sole discharge diagnosis was concussion (ICD-8: 850);

- Double concussion: patients who on two separate occasions over the same time period had been admitted to hospital for not more than one day and on both occasions with the sole discharge diagnosis of concussion;

- Cranial fractures: patients who had been admitted to hospital with a discharge diagnosis of cranial fracture (ICD-8: 800, 801 , 803), with or without concussion but without identified cerebral lesions;

- Cerebral lesions: patients who had been hospitalised with a discharge diagnosis of cerebral lesions (ICD-8: 851, 852, 853,854 ) with or without cranial fractures or concussion.

\section{Draft board register}

There has been conscription in Denmark continuously since Word War II and at age 18 or shortly thereafter Danish men are required to appear before the draft board which assesses their suitability for military service. Uninterruptedly since 1957 the 
Table 1 Dysfunctional scores (=fail) in relation to diagnosis group

\begin{tabular}{|c|c|c|c|c|c|c|c|c|}
\hline Group & Age (years) & $\begin{array}{l}\text { Admission } \\
\text { (days) }\end{array}$ & Total (n) & Fail (n) & Fail (\%) & $\begin{array}{l}\text { Population } \\
(\%)^{*}\end{array}$ & Odds ratio & $95 \% \mathrm{Cl} \dagger$ \\
\hline \multirow[t]{3}{*}{ Single concussion } & 0 to 5 & & 157 & 31 & 19.7 & 19.0 & 1.05 & 0.71 to 1.55 \\
\hline & 6 to 11 & & 439 & 93 & 21.2 & 19.3 & 1.12 & 0.89 to 1.42 \\
\hline & 12 to 17 & & 374 & 97 & 25.9 & 19.7 & 1.42 & 1.13 to 1.80 \\
\hline \multirow[t]{3}{*}{ Double concussion } & Both 0 to 11 & & 298 & 81 & 27.2 & 19.0 & 1.59 & 1.23 to 2.05 \\
\hline & 0 to $11 / 12$ to 17 & & 162 & 42 & 25.9 & 19.3 & 1.46 & 1.03 to 2.08 \\
\hline & Both 12 to 17 & & 61 & 17 & 27.9 & 19.6 & 1.58 & 0.90 to 2.78 \\
\hline \multirow[t]{3}{*}{ Cranial fracture } & 0 to 5 & & 299 & 63 & 21.1 & 18.9 & 1.14 & 0.87 to 1.51 \\
\hline & 6 to 11 & & 443 & 102 & 23.0 & 19.4 & 1.24 & 0.99 to 1.55 \\
\hline & 12 to 17 & & 219 & 60 & 27.4 & 20.1 & 1.50 & 1.11 to 2.02 \\
\hline \multirow[t]{6}{*}{ Cerebral lesion } & 0 to 5 & 1 to 11 & 75 & 16 & 21.3 & 19.0 & 1.15 & 0.66 to 2.01 \\
\hline & 6 to 11 & 1 to 11 & 166 & 40 & 24.1 & 19.2 & 1.34 & 0.94 to 1.91 \\
\hline & 12 to 17 & 1 to 11 & 135 & 35 & 25.9 & 19.6 & 1.43 & 0.97 to 2.11 \\
\hline & 0 to 5 & $12+$ & 23 & 9 & 39.1 & 18.6 & 2.81 & 1.21 to 6.49 \\
\hline & 6 to 11 & $12+$ & 106 & 38 & 35.8 & 19.0 & 2.38 & 1.60 to 3.54 \\
\hline & 12 to 17 & $12+$ & 134 & 45 & 33.6 & 20.2 & 2.00 & 1.40 to 2.87 \\
\hline
\end{tabular}

*Adjusted for secular trends between 1987 and 2001.

†Calculation based on a population of 25000 (that is, the approximate annual intake of the Danish draft board).

$\mathrm{Cl}$, confidence interval.

assessment has included the administration of a group test for cognitive ability, the Børge Prien Prøve. The test comprises four timed subtests measuring logical, verbal, numerical, and spatial reasoning. In each subtest there are about 20 items and a total score $0-78$ is computed. ${ }^{18}$ Within the draft board's computerised register, a code is recorded indicating whether or not a test performance reached a criterion-namely at least 35 items correctly answered-that is considered adequate for conscription purposes. Performances below criterion are considered dysfunctional. About $10-12 \%$ of men are exempted from appearing before the draft board in person and therefore do not take the test, these being those who can document an illness or condition which would disqualify them from military service-for example, chronic asthma, extreme myopia, and various physical and mental handicaps. Danish men are automatically entered into the draft board's register when they become 18, and their records are deleted when they become 32. We conducted our search of the register in December 2001 to January 2002.

\section{Patient selection}

We selected our initial four patient groups, as defined above, from hospital admissions in the period 1979 to 1993 of male children and adolescents aged less than 18 years. In order to locate patients in the draft board register, however, we had to confine our groups to men born after 1968 (the records of men born earlier would have been deleted at the time of our search) and not later than 1981 (few men born later would yet have appeared before the draft board). Such men would thus have appeared before the draft board between 1987 and 2001 .

Within these constraints we identified 12172 patients with single concussion, 641 with double concussion, 1227 with cranial fracture, and 1008 with cerebral lesions. As the cross linking of the register had to be done manually, we randomly selected 1176 of the single concussion patients (about 10\%). Thus, in all, 4052 patients entered the study. Among the cranial fracture group, $79 \%$ had been hospital inpatients for less than one week (median three days). The median period of hospital admission for the cerebral lesion group was 11 days (interquartile range 6 to 28).

\section{Statistical analysis}

Annual norm tables were obtained from the Danish draft board showing the percentages of dysfunctional test scoresthat is, those falling below the 35 item criterion. Over the 1987 to 2001 period covered by our study there was some fluctuation in these percentages, with a generally declining rate from a high of $21.9 \%$ in 1987 to a low of $17.9 \%$ in 1998 , this decline being consistent with a finding of an overall increase in test scores over that decade, reported elsewhere. ${ }^{19}$ For diagnostic and other subgroupings we therefore calculated odds ratios using population rates adjusted for this annual fluctuation.

\section{RESULTS}

Of the 4052 patients, no record was found for 184 (4.5\%). These would include deaths and emigrations after the injury, and proportions did not vary across the four groups. Of the remainder, 3091 (79.9\%) had taken the draft board test, and $777(20.1 \%)$ had been exempted. The overall mean (SD) age at testing was $19.4(1.2)$ years and did not differ significantly between the four groups $(p>0.4)$. More subjects from the cerebral lesion group had been exempted $(321,33 \%)$ than from the other three groups $(13-18 \%)\left(\chi^{2}(3)=151\right.$, $\mathrm{p}<0.001)$, and within the cerebral lesion group the proportion was higher for those who had been admitted to hospital for 12 days or more $(229,46 \%)$ than for a shorter period $(92,20 \%)\left(\chi^{2}(1)=78, \mathrm{p}<0.001\right)$. However, exemption was unrelated to age at injury $\left(\chi^{2}(2)=1.5, \mathrm{p}=0.4\right)$.

Table 1 shows the odds ratios for dysfunctional test scores among the four diagnostic groups as a function of age at injury and, for the cerebral lesion group, as a function of duration of hospital admission. These are also shown in fig 1. In all cases the odds ratios were above unity, indicating increased rates of cognitive dysfunction scores. For the single concussion group, the odds ratios only reached significance where the injury had been sustained between the ages of 12 and 17 years. A logistic regression confirmed a significant negative association between age at injury and test performance $(\mathrm{p}=0.04)$.

By contrast, the odds ratios for the double concussion group were significant where both injuries had occurred before the age of 12 and where one had occurred before 12 and the other between 12 and 17. The odds ratio for cases where both injuries occurred between 12 and 17 was not less than for the other two age groups, but did not reach significance, possibly owing to reduced statistical power from the smaller sample. A logistic regression revealed no significant relation between age as grouped here and test performance $(p>0.5)$. We found no effect for the time difference between the two injuries. Among 53 cases where the interval was under six months the odds 


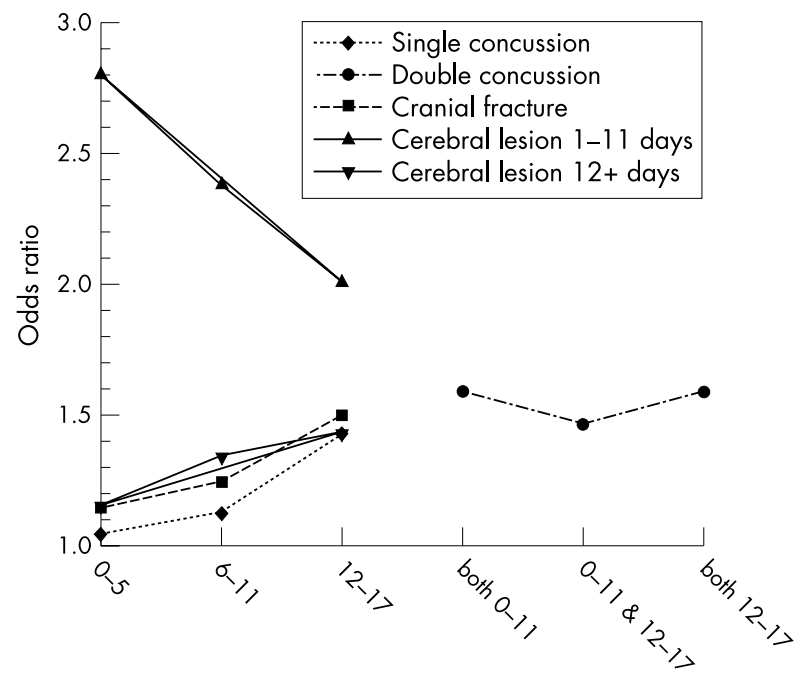

Age (years)

Figure 1 Odds ratios for cognitive dysfunction in relation to age and severity of injury.

ratio was 1.61 (95\% confidence interval (CI), 0.89 to 2.94) and for the remaining 568 cases it was 1.54 ( 1.25 to 1.89 ).

For the cranial fracture group, only the odds ratio for the 12 to 17 year age range reached significance, and a logistic regression confirmed a significant effect of age $(p=0.02)$. There was a weak positive correlation between duration of hospital admission and age at injury for this group (Kendall's $\tau=0.18, p=0.01)$. As shown in table 1 , we divided the cerebral lesion group into those above and below the median number of days of hospital admission. For this group also there was a weak positive correlation between duration of hospital admission and age at injury (Kendall's $\tau=0.15$, $p=0.01)$. None of the odds ratios for cases admitted to hospital for one to 11 days was significant, irrespective of age group. For those admitted for 12 days or more, all odds ratios were significant and were not less than 2.0. The odds ratio was also highest for the 0 to 5 age group, but there were few cases in this group and the confidence interval was correspondingly wide. Logistic regression analysis for the complete cerebral lesion group revealed a significant effect of duration of hospital stay $(\mathrm{p}=0.024)$ but not of age at injury $(\mathrm{p}>0.5)$.

\section{DISCUSSION}

There are two particular strengths of this study. First, it was population based and included all male head injured patients admitted to hospital within the age and calendar year limits. Second, the use of a population administered cognitive test for which full norms are available obviated the often problematic need for control groups. However, there are also some limitations which need to be considered in interpreting our results. First, being based on register data we have only limited information about the nature of the head injury, and for those with cerebral lesions we lack the widely used indices of severity, such as duration of post-traumatic amnesia which is well documented as having strong prognostic value. ${ }^{20}$ Duration of hospital admission is only an indirect measure of severity, although we have shown elsewhere that it is a significant predictor of outcome. ${ }^{21}$ Second, a high proportion $(33 \%)$ of the cerebral lesion group was exempted from testing for reasons not available to us. We may thus be underestimating the effect of serious head injury by including only those well enough to be tested. A third limitation concerns the outcome measure. The Børge Prien test has been shown to correlate highly (0.85) with the widely used Wechsler adult intelligence scale, ${ }^{22}$ and draft board tables for the last 10 years reveal that among young men achieving dysfunctional scores, only 8\% had attended, or were attending, "gymnasia" - the equivalent of sixth form colleges and the gateway to virtually all higher education in Denmark. For those achieving non-dysfunctional scores during the same period, the corresponding percentage was 54. Nonetheless, it is a global screening instrument and it lacks the discriminatory value of tailored neuropsychological batteries. ${ }^{23}{ }^{24}$ Finally, it should be noted that our study is necessarily limited to male subjects only. We are, however, unaware of any sex differences in the effect of head injury on cognitive dysfunction, and furthermore it should be noted that males account for about two thirds of head injuries during childhood and adolescence. ${ }^{25}$

Within these limitations, it is particularly striking, as shown in fig 1 , that the odds ratios for three groupings-namely single concussions, cranial fractures, and relatively moderate cerebral lesions-are almost identical. For all three groupings there is no increase in the rate of cognitive dysfunction as compared with population base rates where the injury occurred before the age of six, and the increase rises to approaching 1.5 where the injury occurred at age $12-17$ years. This finding is open to two interpretations. It might be that mild injuries in early childhood have less effect on adult cognitive functioning than injuries in adolescence, possibly because the severity of injury is less in younger children, where the injury typically results from falls, than in older children, where higher velocity injuries-often traffic related-are more common. ${ }^{25}{ }^{26}$ However, in the present study this has been controlled for in the concussion group by uniformly limiting the sample to patients admitted for at most one day, and among both the cranial fracture and the cerebral lesion groups the correlations between age at injury and duration of hospital admission were weak $(\tau<0.2)$. Alternatively, therefore, it might be that pre-injury risk factors for adolescents are more often associated with developmental, educational, and social disadvantage than in cases of childhood injury. ${ }^{12}$ We have previously found that rates of cognitive dysfunction in young men sustaining concussion are greater where the injury occurred in their early 20s than where it occurred in their late teens. ${ }^{27}$ Reanalysis of these earlier data revealed odds ratios of 1.29 (95\% CI, 1.10 to 1.51 ) for 874 patients injured between ages 16 tol9 and 1.85 ( 1.48 to 2.33 ) for 346 patients injured between ages 20 and 23. These results are also broadly consistent with a hypothesis of increasing psychosocial risk factors in the association between mild head injury and cognitive dysfunction with increasing age. One example of this would be the increasing involvement of alcohol and alcohol abuse in traumatic injuries with increasing age. Recognition of the potential effects of cognition related risk factors for traumatic brain injury is clearly important, as these can confound the association between the injury and any subsequently identified cognitive dysfunction.

In the case of subjects who had sustained double concussions, there was no relation with age at injuries and all odds ratios were about 1.5. Again two interpretations are possible. It could be, as has been suggested, ${ }^{14}{ }^{15}$ that there is a cumulative neurological effect of repeat concussions. Most recent studies have, however, focused on cases where two concussions have occurred within a few months of each other, as it is hypothesised that the brain recovering from one concussion is especially susceptible to enduring damage if a further concussion occurs. ${ }^{28}$ However, we found no effect as a function of time difference between the two concussions, and this might suggest that here too predisposing factors have been operating. ${ }^{29}$ This would imply that cognitive dysfunction related risk factors are independent of age among children who have repeated mild head injuries, but such a conclusion would require further supportive data on these comparatively little studied patients.

Regarding cases with severe cerebral lesions involving hospital admissions for longer periods, our study supports others 
that suggest that children and adolescents with severe head injury are more likely to have cognitive dysfunction in early adult life. ${ }^{8-10}$ Our present evidence also supports other findings indicating that the long term prognosis for cognitive functioning may not be better for children injured at an early age than later. ${ }^{5-7}$ To the extent that psychosocial risk contributes to a greater degree with increasing age for severe cerebral lesions as well, our findings may be masking a more marked neurological effect of earlier injuries as compared with later ones.

\section{ACKNOWLEDGEMENTS}

We thank Carsten Pedersen for technical assistance and Drs Tom Manly and Agnes Shiel for valuable discussion. The work was supported by a grant from the Danish Ministry of Social Affairs and was approved by the Danish Data Protection Agency and the Medical Ethics Committee for Copenhagen and Frederiksberg.

\section{Authors' affiliations}

T W Teasdale, Department of Psychology, University of Copenhagen, Denmark

A W Engberg, Division for Neurological Rehabilitation, Copenhagen University Hospital, Hvidovre, Denmark

\section{REFERENCES}

1 Middleton JA. Practitioner review: psychological sequelae of head injury in children and adolescents. J Child Psychol Psychiatry 2001;42:165-80.

2 Webb C, Rose FD, Johnson DA, et al. Age and recovery from brain injury: clinical opinions and experimental evidence. Brain Inj 1996; 10:303-10.

3 Finger S. Margaret Kennard on sparing and recovery of function: a tribute on the 100th anniversary of her birth. J Hist Neurosci 1999:8:269-85.

4 Hart K, Faust D. Prediction of the effects of mild head injury: a message about the Kennard Principle. J Clin Psychol 1988;44:780-2.

5 Wrightson P, McGinn V, Gronwall D. Mild head injury in preschool children: evidence that it can be associated with a persisting cognitive defect. J Neurol Neurosurg Psychiatry 1995;59:375-80.

6 Anderson VA, Morse SA, Klug G, et al. Predicting recovery from head injury in young children: a prospective analysis. J Int Neuropsychol Soc 1997;3:568-80.

7 Taylor HG, Alden J. Age-related differences in outcomes following childhood brain insults: an introduction and overview. J Int Neuropsychol Soc 1997; 3:555-67.

8 Nybo T, Koskiniemi M. Cognitive indicators of vocational outcome after severe traumatic brain injury (TBI) in childhood. Brain Inj 1999;13:759-66.
9 Klonoff H, Clark C, Klonoff PS. Long-term outcome of head injuries: a 23 year follow up study of children with head injuries. J Neurol Neurosurg Psychiatry 1993;56:410-15.

10 Cattelani R, Lombardi F, Brianti R, et al. Traumatic brain injury in childhood: intellectual, behavioural and social outcome into adulthood. Brain Inj 1998;12:283-96.

11 Marschark M, Richtsmeier LM, Richardson JT, et al. Intellectual and emotional functioning in college students following mild traumatic brain injury in childhood and adolescence. J Head Trauma Rehabil 2000; 15: 1227-45

12 Satz P, Zaucha K, McCleary C, et al. Mild head injury in children and adolescents: a review of studies (1970-1995). Psychol Bull 1997; 122:107-31.

13 Anderson V, Catroppa C, Morse S, et al. Outcome from mild head injury in young children: a prospective study. J Clin Exp Neuropsychol $2001 ; 23: 705-17$

14 Gronwall D, Wrightson P. Cumulative effect of concussion. Lancet 1975;ii:995-7.

15 Gaetz M, Goodman D, Weinberg H. Electrophysiological evidence for the cumulative effects of concussion. Brain Inj 2000;14:1077-88.

16 Andersen TF, Madsen M, Jørgensen J, et al. The Danish National Hospital Register. A valuable source of data for modern health sciences. Dan Med Bull 1999:46:263-8.

17 Green A. The Danish Conscription Registry: a resource for epidemiological research. Dan Med Bull 1996;43:464-7.

18 Teasdale TW, Owen DR. Thirty-year secular trends in the cognitive abilities of Danish male school-leavers at a high educational level. Scand J Psychol 1994;35:328-35.

19 Teasdale TW, Owen DR. Forty-year secular trends in cognitive abilities. Intelligence 2000;28:115-20.

20 Engberg A. Severe traumatic brain injury-epidemiology, external causes, prevention, and rehabilitation of mental and physical sequelae. Acta Neurol Scand Suppl 1995;164:1-151

21 Teasdale TW, Hansen HS, Gade A, et al. Neuropsychological test scores before and after brain-iniury rehabilitation in relation to return to employment. Neuropsychol Rehabil 1997;7:23-42.

22 Mortensen EL, Reinisch JM, Teasdale TW. Intelligence as measured by the WAIS and a military draft board group test. Scand J Psychol 1989;30:315-18.

23 Manly T, Anderson V, Nimmo-Smith I, et al. The differential assessment of children's attention: the Test of Everyday Attention for Children (TEA-Ch), normative sample and ADHD performance. J Child Psychol Psychiatry 2001;42:1065-81

24 Halperin JM, McKay KE. Psychological testing for child and adolescent psychiatrists: a review of the past 10 years. J Am Acad Child Adolesc Psychiatry 1998:37:575-84.

25 Engberg A, Teasdale TW. Traumatic brain injury in children in Denmark: a national 15-year study. Eur J Epidemiol 1998;14:165-73.

26 Kraus JF, Fife D, Cox P, et al. Incidence, severity, and external causes of pediatric brain injury. Am J Dis Child 1986;140:687-93

27 Teasdale TW, Engberg A. Duration of cognitive dysfunction after concussion, and cognitive dysfunction as a risk factor: a population study of young men. BMW 1997;315:569-72.

28 McCrory P. Does second impact syndrome exist? Clin J Sport Med 2001;11:144-9.

29 Bijur PE, Haslum M, Golding J. Cognitive outcomes of multiple mild head injuries in chidren. J Dev Behav Pediatr 1996;17:143-8. 